\title{
Estrategias de guionado para obras transmediales. Las producciones del equipo DCMTeam, Rosario, Argentina
}

\author{
María Celeste Marrocco \\ Fotógrafa, realizadora y consultora producciones multiplataforma \\ macele4@gmail.com \\ https://orcid.org/0000-0002-4809-5198

\section{Script strategies for transmedia works: The DCMTeam Productions, Rosario, Argentina}

\begin{abstract}
RESUMEN
El presente trabajo explora el concepto de "narrativas transmedia", revisando su contexto de desarrollo y múltiples aportes teóricos que han acompañado su devenir. La atención de la investigación se centra en el proceso de guionado y las particularidades de la forma de abordar narrativas de este tipo. El objetivo general es profundizar en la comprensión de los procesos de concepción y guionado para pensar las estrategias de creación y diseño de universos transmediales. Este análisis permite revisar la distribución y accesibilidad de las propuestas, las estrategias empleadas para la construcción del mundo de la historia y el tipo de implicación que se habilita desde lo "canónico", para la participación de los prosumidores. A partir esto, se analizan las formas narrativas empleadas en algunas de las producciones del equipo DCMTeam de la Ciudad de Rosario,

Argentina. La revisión de estas obras permite mostrar las estrategias empleadas para el desarrollo transmedial analizando aspectos relacionados a la forma de distribución

de las propuestas narrativas, la construcción del mundo de la historia propuesta, los niveles de implicación del prosumidor, y las referencias culturales que su universo incluye. Brindando recursos para pensar nuevas propuestas que quieran expandir el universo narrativo en forma
\end{abstract} transmedial.

PALABRAS CLAVE

Narrativa transmedia; Guión transmedia; Estrategias narrativas multiplaforma; Storytelling.

\section{ABSTRACT}

This paper explores the concept of "transmedia narratives", reviewing its development context and multiple theoretical contributions that have accompanied its evolution. The focus of the research is on the scripting process and the particularities of the way in which this type of narrative is approached. The main objective is to deepen the understanding of the processes of conception and scripting in order to think about the strategies of creation and design of transmedia universes. This analysis allows reviewing the distribution and accessibility of the proposals, the strategies used for the construction of the story world and the type of involvement that is enabled from the "canonical", for the participation of prosumers. Based on this, the narrative forms used in some of the productions of the DCMTeam from the city of Rosario, Argentina, are analyzed. The review of these works allows to show the strategies used for transmedia development, analyzing aspects related to the way of distribution of narrative proposals, the construction of the world of the proposed story, the levels of involvement of the prosumer, and the cultural references that their universe includes. Providing resources to think new proposals that want to expand the narrative universe in a transmedia way.

\section{KEYWORDS}

Transmedia storytelling; Transmedia script; Multiplatform narrative strategies; Storytelling. 


\section{Introducción}

La palabra transmedia, está formada por el prefijo trans que significa "más allá", "del otro lado", "a través de" y media que hace referencia a los medios de comunicación, formando una característica aplicable a diversos relatos que extienden su universo más allá de un solo medio o plataforma y se distribuyen de forma orgánica e integrada por diversos canales y formas de distribución, brindando un fuerte protagonismo a la experiencia del usuario. En este sentido es que se abordará el concepto de "narraciones transmedia", siguiendo la definición de Carlos Scolari: "...un tipo de relato donde la historia se despliega a partir de múltiples medios y plataformas de comunicación, y en el cual una parte de los consumidores asume un rol activo en ese proceso de expansión" (Scolari, 2013, pp. 31-32).

Una buena parte de los abordajes sobre esta temática se centran en la circulación social de estos medios, mientras que otros indagan en sus estrategias de guionado. La presente investigación se ubica en este segundo grupo, apuntando a profundizar la comprensión de los procesos de concepción y guionado dentro de una forma narrativa en pleno desarrollo que se caracteriza por la expansión de su relato e historia, entrelazando medios de diversa naturaleza y recomponiéndolos en un solo universo narrativo.

De este modo, la idea no es aproximarse a los desafíos tecnológicos de la transmedialidad, ni a una perspectiva sociológica o a su dimensión económica, sino a la forma en que la multiplicación de dichos soportes afecta a la construcción de sentido. Se quiere indagar en las estrategias de creación de universos narrativos y los procesos para desarrollar el entramado de obras específicamente transmediales, o con orientación multiplataforma. A través del análisis de los trabajos del equipo DCMTeam, se busca explorar las estrategias que se pueden emplear para mantener la coherencia y articulación entre los elementos narrativos que conforman un universo transmedial.

En este punto es importante señalar que el presente artículo es una abreviada presentación de la tesis de su autora, en el ámbito del Doctorado en Artes, Facultad de Artes, Universidad Nacional de Córdoba, Argentina.

\section{Metodología}

Se tratará de responder a una primera inquietud que se constituye en objetivo general de la investigación: Comprender las particularidades de los procesos de concepción y las estrategias que se pueden emplear en el guionado de propuestas transmediales.

Con esta idea en mente, se aborda una primera revisión teórica de los conceptos generales y puntuales relacionados, surgiendo algunas preguntas particulares que guían el camino de análisis, planteando los siguientes aspectos a trabajar:

- Reconocer los procesos que aplican al desarrollo de guiones multiplataforma.

- Identificar estrategias empleadas en las propuestas transmediales para mantener la coherencia narrativa junto a la especificidad de cada plataforma.

- Indagar cómo puede trabajarse el desarrollo de personajes y las dimensiones espaciales, temporales y narrativas en función de la transmedialidad.

Las respuestas a estas preguntas se abordan a través de la investigación y el análisis del proceso de creación de los realizadores de producciones transmediales argentinas, particularmente en la ciudad de Rosario. La propuesta metodológica con la que se trabajó partió de un relevamiento conceptual de las teorías, reflexiones y propuestas de abordaje relacionadas tanto al propio concepto de narraciones transmediales, como a la escritura de guiones orientados a este tipo de relatos. A partir de ella, en este artículo, se proponen algunos elementos de análisis para el guión transmedia, que se aplican al corpus seleccionado, relacionados a:

- La distribución de los medios.

- La construcción del universo

- La vinculación con el prosumidor

- Las referencias culturales que muestran esos mundos narrativos.

Al iniciar el proceso de investigación, se analizó la producción transmedial en el territorio argentino, destacándose el trabajo realizado por un polo de producción en la Ciudad de Rosario debido a su carga teórica, pero también al sostenimiento en el tiempo del tipo de producciones realizadas. En base al interés que despertaron estas producciones, por la densidad de sus estructuras narrativas y la producción permanente que se puso de manifiesto, se decidió centrar los modelos de análisis propuestos en sus estrategias de guionado.

Se trata del equipo DCMTeam', que surge como equipo de producción del proyecto DocuMedia, dirigido por el Mgtr. Fernando Irigaray, dentro de la Dirección de Comunicación Multimedial dependiente de la Secretaría de Comunicación y Medios de la Universidad Nacional de Rosario. Se conforma el equipo en el año 2008, con nueve miembros de perfiles polifacéticos. Como señala Lovato, el equipo funciona como un laboratorio de innovación, a la vez que como productora y medio de comunicación (Lovato, 2017, p.735). Este equipo concentra la experiencia de trabajo permanente, junto a la investigación y el desarrollo teórico, que se suman para lograr producciones de alto compromiso social, con carácter experimental en sus 
desarrollos innovadores y en sus estrategias de guionado.

El sitio web oficial del equipo, en su carácter de productora de contenidos, da cuenta de sus diversas realizaciones en diferentes plataformas, sin embargo, en este trabajo, nos centramos en tres de sus producciones transmediales:

- Tras los pasos del hombre bestia (DCMTeam, 2013)

- Mujeres en venta (DCMTeam, 2014)

\section{- De barrio somos (DCMTeam, 2018)}

Los tres proyectos trabajan estrategias de guionado claras y desarrolladas en su totalidad por el equipo, pudiendo verse sus formas de trabajo y las reflexiones teóricas a las que dan lugar. El intervalo de tiempo en el que fueron realizadas nos permite hablar de tres momentos diferentes en el desarrollo, el tipo de producción y el pensamiento teórico de este grupo. De hecho, dan cuenta de su proceso de investigación y la manera progresiva en que fueron haciendo propias las teorías de trabajo internacionales y les fueron dando su propio acento en el diseño de la estructura narrativa, pero también en la forma de trabajo y las temáticas trabajadas.

Una vez que se determinó la forma y el material con el cual se trabajaría, comenzó el proceso de revisión y análisis de algunos debates y propuestas desarrolladas en el campo teórico que analiza los universos transmediales.

\section{Estado de la cuestión}

El contexto mediático actual nos permite ver cómo las formas de vincularse de las generaciones más jóvenes con los universos narrativos de su preferencia, se diferencia mucho de las evidenciadas en siglo XX. Ellos eligen qué quieren ver, acceden a contenidos seleccionados, personalizables y adecuados a sus propios intereses, afectando incluso su forma de relacionarse y ver el mundo. Como lo señalaba Marshall Mc Luhan en su libro El medio es el masaje, "las sociedades siempre han sido moldeadas más por la índole de los medios con que se comunican los hombres que por el contenido mismo de la comunicación" (Mc Luhan y Fiore, 1969, p.8).

Para estas generaciones, no se trata solo de consumir contenido sino, y tal vez de forma central, de vivir experiencias en esos universos: competir en cosplay; intercambiar información sobre los universos narrativos que más les interesan; reconstruir sus propias fan fictions, donde los personajes viven las historias que ellos desean; desarrollar juegos de rol que permiten construir complejas tramas; acceder a plataformas virtuales con nuevas historias de personajes ya consagrados $y$ algunos otros nuevos, e incluso entrelazando universos muy diferentes entre sí. Estas experiencias se han expandido hasta vincular distintos grupos etarios, sociales y hasta económicos.
Ante esta creciente vivencia, la narrativa se ha adaptado, presentando universos expansivos. En ese camino se encuentra el concepto de "narrativas transmediales".

\subsection{Definiendo las narrativas transmedia}

Cuando se habla de transmedialidad, se hace referencia a una estrategia que crea un mundo narrativo complejo expresado en diferentes medios y lenguajes. En cualquier proyecto de este tipo, la historia se despliega a través de una variedad de plataformas, de modo que cada una de ellas aporta con lo mejor que sabe hacer. Jenkins explica el concepto diciendo:

En la forma ideal de la narración transmediática, cada medio hace lo que se le da mejor, de suerte que una historia puede presentarse en una película y difundirse a través de la televisión, las novelas y los cómics; su mundo puede explorarse en videojuegos o experimentarse en un parque de atracciones. Cada entrada a la franquicia ha de ser independiente, de forma que no sea preciso haber visto la película para disfrutar con el videojuego y viceversa. (Jenkins, 2008, pp. 101-102)

Pratten explica su conceptualización de las narrativas transmedia diferenciando la experiencia que se tenía de un universo narrativo en pleno siglo $X X$, cuando cada pieza en paralelo (filme, juego, libro) tenía su propio desarrollo, de manera que podía ser consumido por separado por el espectador. Mientras en las propuestas transmediales, cada plataforma narrativa se integra logrando formar una experiencia total que es mayor que la suma de sus partes, generando el placer de experimentar la totalidad de la narración transmedia (Pratten, 2015, p.3).

Lisbeth Klastrup y Susan Tosca, por su parte, hablan de "mundos transmediales" como sistemas de contenidos abstractos brindando un repertorio de historias y personajes que pueden ser llevados a variedad de plataformas. En todas ellas, tanto las audiencias como los desarrolladores comparten una idea mental de su mundo, "worldness", formada por una serie de factores que los distinguen y que mientras se mantengan constantes, no obstaculizan que la narración sufra modificaciones de uno a otro medio o a lo largo del tiempo (Klastrup, y Tosca, 2004, p.1).

Max Giovagnoli habla de "transmediaversos", apuntando también a universos narrativos regidos por sus propias reglas, que pueden contener diversidad de historias en diferentes medios. Esto implica que el diseñador transmedia se constituya en una especie de arquitecto, que propone una estructura a ser explorada, permitiendo a los participantes desarrollar su propia experiencia dentro de la propuesta (Giovagnoli, 2017). Estas definiciones resultan en una serie de elementos que cada autor va sistematizando para establecer qué se entiende por narrativas transmedia, con lo cual cada uno pone el acento en 
aspectos particulares de lo que conforma un sistema transmedial.

Scolari retoma de Jenkins los principios que permiten pensar un proyecto de este tipo. Carolin Handle Miller, analiza las características de una narrativa digital, trabajando sobre los videojuegos y su vinculación con las audiencias (Miller, 2008). Sus aportes permiten pensar algunos aspectos particulares de esa relación; retomados también por Acuña y Caloguerea (2012). Jeff Gómez, productor transmedial entrevistado por Scolari, plantea una serie de principios con respecto a la transmedia que apuntan principalmente a su forma de producción (Scolari, 2013), sumando otros referidos tanto a lo narrativo como a lo empresarial, en el artículo "The 10 Commandments of 21st Century Franchise Production"(Gomez, 2012). Robert Pratten presenta sus propios principios sobre el relato transmedia, centrados en lograr una experiencia inmersiva y disfrutable para las audiencias participantes (2015). El investigador brasileño Vicente Gosciola (2003), citado por Renó y Flores, caracteriza a las narrativas transmedia poniendo una la mirada en las redes y la movilidad en la distribución de los relatos multiplataforma (Renó y Flores Vivar, 2012). Renó y Flores también citan las características que José Luis Orihuela plantea para el periodismo transmedia (Renó y Flores Vivar, 2012).

A partir de todos ellos, se pueden extraer las características de una narración transmedial, en la siguiente propuesta:

- Debe extenderse de forma orgánica en diversas plataformas de lenguaje que permitan construir y desarrollar una experiencia narrativa.

- Cada nueva pieza debe articularse con el universo al que pertenece, aportando a la propia historia o a la experiencia narrativa y permitiendo explorar de forma autónoma todo el universo propuesto.

- Puede incluir propuestas narrativas o no, articulando el universo dentro y fuera de los medios o plataformas empleadas, incluyendo sus aspectos de marketing o merchandising.

- Involucra el desarrollo de universos narrativos complejos, amplios e inmersivos en diferentes plataformas, apuntando como eje central a la experiencia narrativa, desde los componentes canónicos hasta los aportes de los prosumidores.

- Permite y estimula una vivencia personalizable según los propios intereses, compartiendo si se lo desea con una comunidad, sin ser necesario explorar la totalidad del universo.

- Es importante considerar desde el canon de la obra los espacios de participación para los prosumidores, y estar atentos a las nuevas apropiaciones no previstas que ellos desarrollen sobre el universo.

La construcción de estos universos transmediales requiere considerar formas particulares de desplegarse y vincularse con su audiencia a través de los diferentes espacios que se desarrollen para ese fin.

\subsection{Prosumidor}

Desde una mirada tradicional se plantean dos polos opuestos: el autor que concibe una obra para ser aprecida por un espectador pasivo que observa una obra. Sin embargo, la realidad de la cultura de la participación ha puesto en cuestión esta dicotomía. Siguiendo a Jenkins, podemos decir que se puede observar

un modelo de cultura más participativo que considera al público no solo como consumidores de mensajes preconstruídos sino como personas que están dando forma, compartiendo, re-enmarcando y remezclando el contenido de los medios de una manera que antes era quizás inimaginable. (Jenkins et al., 2015, p.24)

El concepto de prosumidor surge de un acrónimo formado por dos palabras en inglés: productor y consumidor. Según Renó, ya en 1968, el autor brasileño Decio Pignatari propuso la idea de un ciudadano produsumidor (Renó, 2019, p.18), pero será recién en la Tercera Ola de Alvin Toffler cuando el concepto de prosumidor (Toffler, 1987, p.44) alcance su reconocimiento en el mundo académico, como las personas que consumen y producen contenido lo comparten con sus compañeros o lo distribuyen gratuitamente; reduciendo la brecha entre consumidor y productor.

Es el prosumidor quien decide el camino a seguir para adentrarse en la propuesta de la narrativa, para penetrar su historia, según las posibilidades y puertas de acceso que el emisor le proporciona. Es por ello que muchas experiencias transmedia están diseñadas tendiendo a lo social, a la participación y el compromiso de su público en comunidades reales y virtuales, alcanzando una fuerte vinculación con el universo o la propuesta, sea de ficción o no.

Podemos coincidir con Renó y Flores cuando señalan que se trata de audiencias participativas, reconstructoras de contenidos a partir de los discursos disponibles y sus enlaces. El relato transmedia es polifónico y se mueve en un espacio cada vez menos gobernable (Renó y Flores Vivar, 2012, p.40). No es entregado como un objeto acabado, sino como un objeto propuesto que permite y requiere completar su construcción. Para eso, audiencias dispuestas a explorar, comunicarse y crear son la forma de hacer crecer estos universos.

Paralelamente, el polo creador verá afectada su concepción tradicional, ubicándose en un lugar donde haber escrito algo 
fijo e inmutable será solo una parte de su trabajo, ampliado por la posibilidad de crear y organizar las estructuras expresivas que componen una historia multiforme, mostrando una estructura narrativa fragmentada que contempla los trayectos de lectura potenciales. Analizar el trabajo que se debe realizar para estructurar estos universos propuestos, se vuelve entonces de vital importancia para los creadores multiplataforma.

\section{Diseñando universos}

Los conceptos de diversos autores permiten desarrollar categorías de trabajo y análisis para abordar el corpus seleccionado, a la vez que pueden constituirse en recursos para los creadores que se proponen abordar una propuesta transmedial. Max Giovagnoli (2017), señala que una propuesta transmedial puede apuntar a audiencias heterogéneas, recurriendo a diversos lenguajes y medios en su propuesta, tomando personajes de diferentes mundos significantes, realistas o no, y recombinándolos en nuevas y diversas configuraciones. Esas narrativas se podrán expandir tanto en contenidos (video, imágenes, textos, sonidos, etc.) como en experiencias (propuestas inmersivas, instalaciones, experiencias virtuales, etc.) (Giovagnoli, 2017, pp. 14-50).

A esto se suma lo que señala Marsha Kinder (Kinder, 1991, p.38) cuando habla de una matriz intertextual aportando la idea de sistema para abordar una propuesta narrativa multiplataforma. Por su parte, basados en la lectura de Klastrup y Tosca, Hernández Pérez y Grandío, plantean diversas relaciones entre los medios que componen un proyecto, organizando los elementos disponibles en cuatro áreas: una que releva los medios que la componen, otra que revisa la estructura narrativa de la propuesta, una que analiza las referencias intertextuales del proyecto $y$, finalmente, una que analiza la forma de distribución y su vinculación con su público (Hernández Perez y Grandío Pérez, 2011, p.10).

Robert Pratten, en el mismo sentido, propone analizar diversas capas que incluye el diseño de relatos transmediales:

- Capa de la experiencia: describe el viaje emocional de la audiencia.

- Capa de la narrativa: describe el desarrollo en términos de acciones y personajes.

- Capa de la presentación: describe los medios, canales y plataformas sobre las que se distribuyen las capas anteriores.

- Capa de la interactividad: describe la mecánica los eventos y la lógica que distribuye la experiencia. (Pratten, 2015, p.98)

Se puede ver que la idea de pensar diversas dimensiones para poder abordar una propuesta de este tipo, es una constante, con características comunes entre los diversos autores. Por ello, a partir de estas visiones, se proponen cuatro aspectos fundamentales para abordar estas estructuras narrativas:

- En cuanto a su distribución y accesibilidad: se analizan cada una de las piezas y relatos particulares que forman parte de la propuesta. Se revisará cómo se enlazan unos con otros y la relación narrativa que se produce entre ellos. Se reconocen los hilos narrativos principales que estructuran la macrohistoria. Y finalmente se identifican los elementos que se constituyen en pistas de migración2 externas que generan el interés de los prosumidores en la propuesta concreta a analizar.

- En cuanto a la construcción del mundo de la historia: se comenzará por identificar la manera en que se estructura, el género de la macrohistoria, reconociendo las pistas de migración interna que inviten a los prosumidores a recorrer la propuesta en su totalidad, siguiendo el desarrollo de los personajes que se mueven en ese universo.

- En cuanto a los niveles de implicación del prosumidor: se buscará identificar la manera en que se construye la experiencia. Para ello, se reconocerán las mecánicas de interacción y participación desarrolladas.

- Finalmente, en cuanto a las referencias culturales del universo narrativo: se parte de reconocer la premisa de la propuesta buscando identificar la relación que se logra establecer con su público.

\subsection{Revisión del corpus}

Para iniciar el análisis del corpus, se debe revisar cómo se componen cada una de las propuestas transmediales seleccionadas:

- Tras los pasos del Hombre Bestia (DCMTeam, 2013): Toda la narrativa gira en torno a la primera película de ciencia ficción que se realizó en Argentina, El Hombre Bestia (Zaccaría Soprani, 1934). A partir de la investigación sobre el paradero de la última copia de esta película, se desarrolla una propuesta transmedial que atraviesa diversos productos en diferentes plataformas, incluyendo el trabajo en medios tradicionales, entornos digitales y acciones territoriales.

Mujeres en venta (DCMTeam, 2014): aborda la problemática de la trata de mujeres en Argentina. El proyecto da cuenta de la realidad que rodea al equipo, por medio de un entramado de medios: un documental multimedia, un documental televisivo, webpisodios, libros y entrevistas, a los cuales se puede acceder desde el espacio virtual que concentra toda la propuesta.

De barrio somos (DCMTeam, 2017): centra la mirada en los clubes de barrio de la Ciudad de Rosario. La temática abordada promovió la recuperación de plataformas tradicionales como los álbumes de figuritas o las kermeses, integrando lenguajes digitales y analógicos como parte de su estrategia de 
expansión. El objetivo de la propuesta fue recorrer y explorar la geografía de la ciudad, compartiendo con sus vecinos las características de su idiosincrasia e historias particulares.

\section{Distribución y accesibilidad}

En las tres propuestas el espacio es importante como parte de la construcción narrativa y elemento significativo dentro de la expansión transmedial. Tras los pasos del Hombre Bestia propone la exploración del espacio real por parte de los participantes; en Mujeres en venta, hay un nivel de significación del espacio como parte de la narrativa que guía la propuesta y su reconstrucción virtual para la denuncia de delitos. Mientras, en De barrio somos, es el espacio real el que permite la participación en los propios clubes, a la vez que su reconstrucción virtual vehiculiza la exploración de este.

La estructura narrativa de cada una de las propuestas permite ver cómo se articulan los medios que la componen dentro de la macrohistoria de cada una. En Tras los pasos del Hombre Bestia, el universo se estructura en dos niveles diegéticos. Por un lado, la historia interna de El Hombre Bestia, producida en 1934, y por el otro, la narración sobre su historia desplegada en la propuesta transmedial. Los dos niveles se interrelacionan entre ellos sobre todo en el momento de las intervenciones urbanas, cuando se difunde la idea de que el Hombre Bestia ha llegado a la ciudad de Rosario.

Se puede identificar como obra seminal la propia película El Hombre Bestia, según la propuesta de Scolari y Heredero Díaz (García Carrizo y Heredero Díaz, 2015), y como obra núcleo el documental para televisión Tras los pasos del Hombre Bestia. Además, se brinda información que expande la narrativa en historias paralelas por medio de las ucrónicas, las pistas de realidad aumentada, el mapa geolocalizado y el documental multimedia. Como historia previa al documental, se ubica la serie de movisodios, a los que se considera precuela. Como historias periféricas se ubican el making off y las redes sociales, los perfiles de Twitter permiten profundizar a los personajes. Las intervenciones urbanas se ubican como historias intersticiales, cuyo objetivo fue generar intriga en el público sobre la película original y estimular la participación en la propuesta transmedial.

Si se intenta identificar los hilos narrativos se verá que la idea principal es la búsqueda de las últimas latas de la misteriosa película, siendo el desarrollo de dos de sus personajes, Colman e Irigaray como el investigador, lo que guía ese recorrido.

En Mujeres en Venta se puede considerar como obra seminal, el webdoc que brinda acceso al resto de los medios. Sin embargo, la obra núcleo que congregó la mayor atención y difusión fue el documental televisivo. Se puede reconocer como espacios de difusión la campaña gráfica con realidad aumentada, las intervenciones urbanas o la publicidad en LEDs. Todas ellas apuntaban a generar conciencia sobre la problemática y no a publicitar directamente la propuesta. Los micros televisivos se convirtieron en elementos que completaban información del documental, comportándose a manera de avance de este. El comic, difundido en papel, presenta una historia paralela al resto de las piezas.

Por su parte, el mapa geolocalizado -espacio de interacción para los prosumidores-, era accesible desde el inicio de la propuesta a través del documental multimedia. Este mapa construye una historia paralela, con diversas historias individuales narradas por los prosumidores y enlaces a fuentes periodísticas sobre cada reporte. Finalmente, las redes sociales, si bien brindan espacio para comentarios, se limitan a publicar el recorrido y la repercusión de la propuesta transmedial, por lo que las se consideran periféricas.

Todas historias particulares coinciden en establecer ciertas etapas en el proceso, que llegan a constituirse como el hilo narrativo central basado en la evolución del conflicto retratado: el primero es la captación; el segundo es el traslado y ablande, generalmente en zonas intermedias del país como Córdoba o Santa Fe, donde un jefe violento logra aterrarlas y torturarlas para que después pasen a manos de alguien menos agresivo que en comparación parece una gran persona $y$, quebradas, se resignen a esta forma de esclavitud; en un tercer momento son movidas al sur del país donde trabajan, en particular, en zonas de actividad petrolera o minera. Finalmente, para algunas de ellas, llega el momento del rescate, donde son llevadas a otras zonas para la recuperación de su identidad.

En De barrio somos, no hay elementos que puedan ubicarse como precuelas o secuelas, ya que el desarrollo de la dimensión temporal de la narrativa no es un factor determinante, sino que las diversas historias se presentan en forma paralela una a otra, complementando algunos aspectos particulares de la narración con elementos como la realidad aumentada o las figuritas. Los microepisodios pueden ser vistos como profundización de personajes, cuando por ejemplo se narra la experiencia de una familia que descubre entre las figuritas a su abuelo. En el resto de los casos, se trata de historias pequeñas que forman el entramado general, centrándose en clubes particulares o breves historias significativas. El Webdoc funciona como eje. Las redes sociales son el espacio que se destina tanto a la difusión de la propuesta como a la relación con el público, mucho del cual forma parte de las comunidades de cada club representado. Las kermeses se revelan como los puntos de máxima interacción con el público, completando la historia al vincularla con sus espectadores y participantes.

En esta propuesta en particular, los hilos narrativos son solo temáticos; se enfocan en el desarrollo de un concepto central: la relación de las instituciones con el medio en el que se desarrollan y las personas que participan de sus actividades. En cada pieza de los episodios, se destaca la presencia de uno de los clubes o de personajes particulares, sin una historia 
central que evolucione y haga avanzar la narración en un solo sentido.

Cada una de las propuestas construye su propio universo de manera diferenciada. En el primer caso, el tiempo narrativo es el eje vertebrador de las piezas, alrededor de las cuales se puede ir tramando la narrativa. En el segundo caso, en cambio, la apuesta por generar conciencia sobre la problemática trabajada es el conductor que va enlazando cada uno de los medios que componen la propuesta. Finalmente, en el tercer caso, la exploración de la importancia de cada espacio representado es el vínculo que dinamiza el entramado narrativo.

Las pistas de migración externa incluyen el diseño visual de cada propuesta, logrando que las temáticas principales se vuelvan el eje de diseño, tanto a nivel estético como a la hora de seleccionar los medios que componen cada propuesta. De esta manera, la integración de una imagen fuertemente fundamentada y plataformas acordes le dan a cada universo una notoria coherencia interna que los vuelve significativos para sus públicos. En cada propuesta, el desarrollo narrativo de su universo permite visualizar las estrategias de narración empleadas por sus creadores.

\section{Construcción del mundo de la historia}

Se puede observar que la estructura narrativa responde a las expectativas comunicacionales de cada narración. En Tras los pasos del Hombre Bestia parte cada uno de los textos apunta a avanzar en el arco de la macrohistoria, con un sutil desarrollo de los personajes participantes. Cabe señalar que la trama desarrollada en el texto seminal solo es retomada y de manera general, dentro de los textos de difusión en las intervenciones urbanas.

A nivel de macrohistoria, se hace uso de una estructura en donde cada texto emplea diversos elementos de la diégesis total para aportar desde su lugar a la propuesta general, cada uno con su propia lógica y narración interna conectándose con el resto, pero también pudiendo ser explorados de forma independiente hasta completar una construcción de sentido propia de cada uno de los medios.

Mujeres en venta, a nivel de estructura también muestra una narrativa donde cada pieza va sumando información y desarrollo dramático. Aunque en el caso del comic, si bien respeta el mismo hilo narrativo, se muestra una historia paralela independiente de las tres que se relatan en el resto de las piezas transmediales. La relación entre las diversas visiones sobre la problemática que se van organizando en las diversas piezas que componen la propuesta, muestra múltiples capas, que a medida que son descubiertas por el público, le brindan mayores detalles sobre las historias narradas y la situación general.

De barrio somos se caracteriza por una trama donde cada pieza de la red narrativa cuenta una historia cerrada, enla- zada con la siguiente por sus ideas temáticas y estéticas, de modo antológico, presentando nuevos personajes con su propia historia. Cada pieza permite ver nuevos aspectos de una macrohistoria, que pone el acento en la importancia de esos espacios para la mejora de la integración social y la participación de los vecinos.

Respecto al género, cada plataforma abre nuevas posibilidades puesto que puede variar de una a otra, lo cual se vuelve muy difícil de abarcar. A nivel general, Tras los pasos del Hombre Bestia se presenta como un documental ficcionalizado, que recurre a elementos de la novela y el cine negro para su construcción narrativa y al cine fantástico, retro y clase B en su opción estética.

Mujeres en venta, trabaja con la estrategia de los documentales de entrevista televisivos, tanto el propio documental, como el webdoc, los movisodios o los micros para televisión. Sin reconstrucciones, pero con imágenes intercaladas que sirven de metáforas o subrayan las ideas vertidas por los entrevistados. Todos responden a una misma estética visual y el mismo ritmo narrativo, por lo cual se puede clasificar como documental. Pero las diversas plataformas hacen un uso particular de las estéticas seleccionadas.

De barrio somos presenta piezas que aportan nuevos puntos de vista sobre la idea general que trata de comunicar la macrohistoria y a partir de las cuales se propone un formato en capas que permite ir profundizando en el universo. En los episodios de la serie web se trabaja por medio de entrevistas de tipo informativo donde los personajes cuentan a cámara su historia con fuerte acento en el montaje expresivo. En cambio, los microepisodios para redes sociales, por medio de imágenes representativas y textos sobre impresos, registran ciertas historias particulares de manera breve y dinámica, aproximándose más a un spot publicitario con una compilación de datos.

Cada una de las propuestas ha construido, a lo largo de su entramado, pistas para enlazar las diversas plataformas, de manera más evidente y fuerte para la investigación sobre El Hombre Bestia, mientras se va haciendo más laxo ese enlace en Mujeres en venta, y casi inexistente entre los clubes de barrio rosarinos.

Se puede tomar como ejemplo el documental televisivo de Tras los pasos del Hombre Bestia que comienza con el Investigador visionando el video que lleva en sus manos en un sobre de papel madera, el cual se puede rastrear en la serie de movisodios, cuando Colman lo obtiene en la universidad y posteriormente se lo entrega al Investigador. De la misma forma, en los movisodios, cuando Colman contacta a un empleado de un negocio de comics que tiene una entrevista de interés para el Investigador, Colman se lo comunica y en el documental se presenta el material. También se escucha a Colman buscar un cuaderno de recortes cuyas impresiones se encuentran en manos del Investigador posteriormente. 
En cambio, para Mujeres en venta, son pocas las pistas y se limitan a colocar las direcciones de redes sociales y de la página del webdoc en todas las plataformas. Al visionar una de las piezas surgen preguntas, estimulando esa capacidad negativa ${ }^{3}$ del relato que le permite al prosumidor interrogarse por otros aspectos de la problemática a lo que los micros, o los webisodios, pueden dar respuesta. Se confía más en lograr que el tema interese a los espectadores - guiando su atención y orientándolos a investigar-, que a la narrativa propiamente dicha.

Lo mismo sucede con De barrio somos, cada relato va sumando una institución diferente, estimulando a los miembros de esta a explorar la propuesta, y es por ello que una de las principales pistas de migración se da en las kermeses. En estos eventos no solo se distribuyeron juegos, figuritas y libros, sino que también se proyectaron los episodios. De esa manera, estos eventos pueden funcionar como puertas de acceso a la experiencia y generar al mismo tiempo un estímulo a recorrer las plataformas.

Respecto a los personajes, en Tras los pasos del Hombre Bestia, debido a su carácter híbrido de docuficción, muchos participantes están solo consultados como entrevistados y no como personajes, mientras otros han sido incorporados propiamente como tales:

- Investigador Fernando Irigaray: el realizador se coloca a sí mismo como un personaje, tanto dentro del documental como de los movisodios; es quien contrata al Detective.

- Detective Marcelo Colman: personaje de ficción que reúne las pistas que el Investigador necesita y propone a los prosumidores participar de esta búsqueda.

- Camilo Zaccaría Soprani: el realizador de la película original, convertido en personaje en los relatos del documental, los movisodios y los webisodios, así como en su perfil de Twitter.

- Orson: vendedor de comics que le brinda al Investigador una de las entrevistas.

- El Hombre Bestia: personaje desarrollado dentro de la película original cuya sombra se extiende sobre la transmedia actual.

En Mujeres en venta, si bien se trata de un documental, se construye a sus entrevistados como personajes. Los principales son Zulma, Elizabeth y Vanesa. Otro personaje importante es Sofía, presentada en el comic con una historia de vida muy similar a la de sus compañeras. El único tratante que se puede ver en la narración es quien engaña a Sofía en el comic, presentado como un hombre desagradable, que se une al dueño del prostíbulo y sus clientes para atormentar a esta joven paraguaya.
En el último caso, De barrio somos no presenta personajes que atraviesen la macrohistoria, sino que se puede hablar de algunos personajes en el mismo sentido que en la propuesta anterior, pero cada uno desarrollado en tan solo un episodio de la serie documental o en un capítulo del libro. Sin embargo, los clubes como instituciones son tratados y presentados como personajes en sí mismos.

En los tres casos, la forma de presentación de los personajes tiene factores en común en su construcción, que permiten la identificación y el compromiso de las audiencias, pero se diferencian en la profundidad de desarrollo de cada uno. Colman será delineado con mucho más detalle, por ejemplo, que los personajes de los clubes deportivos. Esto parece ir de la mano con el objetivo narrativo y temático de la propuesta, donde mientras más fuerte es el compromiso con la comunidad y la temática, los personajes particulares parecen desdibujarse en preocupaciones comunitarias.

Respecto a la focalización cada propuesta construye su propia forma de abordar la narración. Se puede ver que se brinda una focalización general en los tres casos, común a toda la propuesta, aunque el punto de vista desde donde se narre cada pieza pueda variar para subrayar diversos aspectos de la narrativa completa que se está presentando, expandiendo el universo presentado. En este punto, llega el momento de abordar la manera en que cada propuesta se vincula con los prosumidores.

\section{Niveles de implicación del prosumidor}

Si bien los tres universos analizados muestran un alto grado de control autoral, el espacio pensado para la interacción y participación difiere de una a otra. En Tras los pasos del Hombre Bestia funcionó un mecanismo que muestra las tres etapas planteadas por Dena (2009):

- Detonación 4 : las intervenciones urbanas, al igual que las tarjetas de promoción de realidad aumentada, son la puerta de acceso a la narrativa. A esto se sumó una serie de trailers y presentaciones en video que se difundieron por diversos medios, además de publicaciones de diarios donde las ucronías y una serie de artículos anunciaron y presentaron el proyecto.

- Remisión $n^{5}$ todas estas puertas de acceso incluyeron información de las direcciones virtuales por medio de las cuales se podía acceder a los diversos medios que componen la propuesta.

- Recompensa $a^{6}$ la participación se recompensaba con la posibilidad de una competencia presencial por premios, difundido previamente en las redes sociales. En la participación lúdica del documental multimedial, se reúnen conocimientos de acceso abierto a todo el que desarrolle la experiencia de prosumidor. 
La propuesta tiene un alto grado de control autoral, con muy pocos espacios para que la participación de los prosumidores afecte la narrativa, brindando solo espacios para comunicar ideas por medio de las redes sociales y accionando búsquedas que les permiten recorrer y analizar el espacio real como un lugar a explorar. Se trata de una serie de mecánicas de interacción basadas en la exploración y el juego (en base a la recolección de puntos, el uso de las locaciones y diferentes puntos de vista).

En Mujeres en venta, el grado de participación prevista es reducido, circunscripto solo a la posibilidad de hacer denuncias anónimas en el mapa geolocalizado y comentarios en las redes sociales, pero sin intervenir de forma significativa en la experiencia narrativa. Se producen diversas formas de detonación y extensos espacios de remisión:

- Detonación: se destacan los trailers televisivos, las gráficas en la vía pública, los panfletos en mano y las proyecciones en Leds. También la difusión en papel de los comics resulta una forma de despertar el interés y como una nueva puerta de acceso. De la misma manera, las redes sociales se encargaron de diseminar la convocatoria.

- Remisión: en este punto se puede ubicar la estrategia permanente de brindar los datos necesarios para acceder al webdoc o el resto de los recursos, incluyendo en la página del documental multimedia un espacio para recorrer todo el mapa transmedial.

- Recompensa: la propuesta no genera otro tipo de recompensa que no sea el acceder a la información y formar parte de una comunidad unida por una idea y un objetivo de lucha.

La información está disponible y al alcance de los prosumidores, con cierto nivel de repetición de datos entre los diversos medios, limitando el intercambio entre los prosumidores a comentarios en las redes sociales. Las mecánicas de participación son limitadas aún dentro del webdoc, el cual solo permite que los espectadores puedan seleccionar por cuál capítulo comenzar el visionado y su secuencia, pero no brinda espacios para interacción significativa de ningún tipo. El resto de los medios, con excepción del mapa geolocalizado y las redes sociales, no muestran ningún espacio de interacción.

De barrio somos muestra también poco espacio para la participación, que solo se ejerce dentro de los eventos comunitarios tipo kermese, donde pueden ser parte de la experiencia que proponen los clubes. Esta participación no afecta el desarrollo de la narrativa. Se pueden catalogar algunos espacios específicos de detonación, con un amplio concepto de remisión, y recompensas particulares para las audiencias:

- Detonación: se pueden incluir las publicaciones periodísticas, las redes sociales y la gran variedad de gráficas que circularon por estos medios. Además, dentro de los propios clubes, se difundieron publicidades gráficas. Las redes sociales se constituyeron en espacios de difusión de todas las actividades con intercambios poco significativos a nivel narrativo con las audiencias.

- Remisión: el webdoc, como texto núcleo concentró todos los recursos de la propuesta, permitiendo acceder a todas las plataformas que la conforman. En este punto, son sin dudas un espacio fundamental los eventos de kermese donde se puso en acción la participación de los usuarios por medio de juegos tradicionales, pero también a través del juego de mesa, las figuritas y la realidad virtual, todo lo cual permitió que la audiencia viviera la experiencia comunitaria del club.

- Recompensa: la principal recompensa fue el poder evocar y vivir esa experiencia, reuniendo las figuritas o participando de los eventos.

Se generó una experiencia fluida para la audiencia que puede recorrer de forma dinámica las diversas plataformas, donde el uso de las locaciones en forma empírica en los eventos, o virtual, por medio de la realidad aumentada, permitió la participación directa y la suma de puntos de vista que construyen la idea que se transmite a lo largo del entramado narrativo. En el juego de mesa, las figuritas y los eventos de kermese, se propone una experiencia integrada de inmersión, por medio de mecánicas de observación, exploración y juego.

Respecto a la relación que establece la audiencia con cada uno de estos universos, en el primer caso, se parte de una apuesta a un primer lugar de observador para llegar al rol de explorador y poder participar en un aspecto lúdico caracterizado por la reunión de pistas. El viaje emocional se da principalmente desde el espacio de observación al de exploración y apropiación de los conocimientos, lo cual apunta a aumentar el compromiso emocional de los participantes por medio del juego.

La propuesta de Mujeres en venta trabaja fuertemente en la empatía emocional del espectador con las víctimas de trata. Se puede decir que el nivel de observación es el más intenso, seguido por la posibilidad de exploración de la trama en el mapa de medios. De esta forma, el compromiso emocional se afianza y fortalece al tomar historias reales trabajadas con una estética visual comprometida con las emociones de cada entrevistada.

De barrio somos genera un espacio distintivo de participación para los espectadores en el formato de kermese, evocando la participación directa, personal y tradicional de las comunidades que forman los clubes de barrio. Se puede decir que la propuesta puede ser vivenciada de manera individual por medio de la participación directa, jugando el rol real de ser parte de los clubes, por lo que la dimensión grupal es una parte importante de la experiencia. Permite también poder participar de juegos tradicionales, de poca incidencia narrativa, pero que desarrollan y expanden la experiencia. Se subraya la pro- 
puesta de exploración como el componente más destacado de la vivencia de los públicos y la observación como uno de los elementos importantes de la misma.

\section{Universo narrativo}

Poniendo en relación la propuesta Tras los pasos del Hombre Bestia con su espacio cultural de referencia, se puede señalar que la premisa general se basa en rescatar del olvido a un personaje aventurero - el realizador de la primera película de ciencia ficción de Argentina- por medio del género docudrama, respetando una estética que lo aproxima al cine de aventuras y particularmente el de detectives de la primera mitad de siglo XX. La realización busca construir una experiencia que evoque fuertemente el clima de la década de los años 30 en Rosario. Para eso se implementó un universo transmedial que parte de una propuesta de difusión a partir de intervenciones urbanas. Llegando a la presentación de un documental televisivo que difunde la idea central del trabajo, pero también por diversos medios la convocatoria a participar de un documental multimedia interactivo de carácter lúdico, que en forma de búsqueda del tesoro propone a los prosumidores reunir pistas explorando espacios reales y virtuales que les den los datos necesarios para responder a los desafíos y finalmente llegar a una instancia presencial donde, en una suerte de juego de la oca, respondan preguntas, socialicen y compartan con otros.

Se trata de un producto pionero que experimenta, en su momento de producción, caminos con poco recorrido a nivel nacional. Esto hace de la experiencia de Tras los pasos del Hombre Bestia una producción de gran importancia entre la narrativa local, como una de las primeras y más reconocidas producciones en el país.

Ahora, si se revisa el segundo caso, la premisa de la que parte es lograr la sensibilización ante una problemática que es presentada como responsabilidad comunitaria, un tema donde toda la sociedad está involucrada y en riesgo, ya sea por connivencia, exclusión o simple desinterés. El relato muestra crudamente y en primera persona a tres personajes centrales que atravesaron todo este submundo de torturas y violencia, por medio de un género documental que logra una profunda identificación en base al uso de los recursos técnicos. Se insta a los espectadores a no permanecer indolentes ante esta realidad, a tomar posición, sobre todo, dejando de consumir estos servicios y enseñando a no hacerlo. Ese es el punto en donde se logra la interacción, cristalizada dentro de la propuesta como un mapa para registrar denuncias, pero que tiene su real objetivo mucho más allá de los límites narrativos del relato.

En el tercer caso, el entramado está íntimamente enlazado a su universo de referencia. Se trata de rescatar el valor de la vida comunitaria en el contexto urbano y de las tradiciones de vinculación social por medio de la institución del Club como espacio no solo de reunión o práctica deportiva, sino como lugar de desarrollo personal, comunitario y social. Este valor se suma a una fuerte carga evocadora de tradiciones, presentadas casi de modo idílico como lugar de bienestar social y cultura compartida.

De esta manera, la narrativa apunta a generar la experiencia de volver a un tiempo asociado a las tradiciones e identificado en historias particulares. Es por ello que el universo propuesto es amplio, casi ilimitado, pero se narran historias concretas que no tienen vinculación causal entre ellas, sino que solo se asocian por desarrollarse en entornos similares y equivalentes.

Se han visto en cada apartado las similitudes y diferencias que las tres propuestas presentan. En este punto se puede señalar que muestran una suerte de evolución del trabajo de su equipo realizativo. En la primera propuesta se puede observar cómo la narrativa trata de responder a la mayoría de las reflexiones teóricas internacionales sobre el desarrollo de guiones transmediales. Mientras que, en los trabajos subsiguientes, se muestra su progresiva independencia de estos condicionantes, para generar trabajos con objetivos y características propias. En los casos posteriores no se muestran pistas de migración tan fuertes ni claras, pero su apuesta temática y experiencial es el centro del entramado narrativo propuesto. La experiencia es un fuerte sello de estas propuestas, pero sobre todo el fuerte arraigo local de las mismas.

\section{A modo de cierre}

En este artículo se espera haber dado algunos puntos de partida para comprender las estructuras narrativas multiplataforma, destacando la importancia de diseñar universos complejos, brindando mayor libertad de exploración y acción al prosumidor.

Tal como se planteó en los objetivos iniciales, se espera haber aportado a la comprensión de los procesos de concepción de una propuesta transmedial. A la vez que haber dado cuenta de estrategias de diseño que permitan expandir un universo narrativo para su exploración en espacios multiplataforma. Se ha procurado presentar algunos procesos narrativos que permitan pensar cómo mantener la coherencia, respetando la diversidad de plataformas empleadas. En ese sentido se han analizado aspectos relacionados a las dimensiones espaciales, temporales y al entramado narrativo que permite al prosumidor explorar los diversos relatos particulares que la componen y comprometerse con la propuesta. A lo largo del trabajo se han revisado diversos conceptos relacionados con la distribución de plataformas, la construcción del mundo de la historia, los niveles de implicación del prosumidor y las estructuras de referencia de su universo, dentro propuestas 
transmediales.

Es imposible decir que se ha llegado a un punto de cierre respecto a las estrategias que esta forma narrativa emplea en su desarrollo, puesto que cada nuevo realizador propondrá su propia y particular aproximación. Lo que se ha buscado en este trabajo es lograr desarrollar un instrumental que permita abordar los diversos, múltiples y complejos aspectos que involucra el desarrollo de narrativas transmediales. Es por ello que seguramente en los próximos años se verán nuevas propuestas, con formas novedosas de lograr esa experiencia.

\section{Notas al final}

1. Enlace a página web del equipo http://www.dcmteam.com.ar/

2. Se trata de señales visibles al interior de un texto que conduce a contenidos presentes en otros canales, pueden ser internas (narrativas de conectividad ubicadas en la historia que remiten a otras partes del universo) o externas (paratextos por fuera de la narración que brindan una conexión superficial) (Ruppel, 2006).

3. Entendida como estrategias que permiten generar espacios no narrados que evoquen un sentido de incertidumbre, misterio o duda en la audiencia (Gallego Aguilar, 2011), un concepto relacionado con un mensaje que se muestra en varios medios como una forma de crear nuevos puntos de entrada a una historia. Este documento se refiere a sus principios estructurales requeridos para su implementación, y al papel que la cultura participativa tiene en su uso. Además de su definición, se presentan diferentes modelos de creación colaborativa que pueden utilizarse para involucrar al público en el desarrollo de una franquicia de medios. Al revisar la literatura, las experiencias transmedia, los trabajos de los diseñadores transmedia y las entrevistas, este documento identifica los problemas de diseño que una industria creativa en un país emergente debe aplicar para ejecutar iniciativas transmedia.

4. Recursos que activan el relato motivando a las audiencias (Dena, 2009)

5. Piezas que permiten la profundización de las historias (Dena, 2009)

6. Plataformas que brinden una recompensa al compromiso de la audiencia (Dena, 2009)

\section{Bibliografía}

Acuña, F. y Caloguerea, A. (2012). Guía para la Producción y Distribución de Contenidos Transmedia para Múltiples Plataformas. Pontificia Universidad de Chile.
DCMTeam. (2017). De Barrio Somos: Historias de Clubes en 360. Carpeta de guión del proyecto.

Dena, C. (2009). Transmedia Practice: Theorising the Practice of Expressing a Fictional World across Distinct Media and Environments [Tesis para el Grado de Doctor en Filosofía, Universidad de Sydney]. https://ciret-transdisciplinarity.org/biblio/biblio_pdf/Christy_DeanTransm.pdf

Gallego Aguilar, A. F. (2011). Diseño de Narrativas Transmediáticas [Tesis para Maestría en Diseño y Creación Interactiva, Universidad de Caldas]. https://www.researchgate.net/publication/224860276_ Diseno_de_narrativas_transmediaticas_guia_de_referencia_para_ las_industrias_creativas_de_paises_emergentes_en_el_contexto_ de_la_cibercultura

García Carrizo, J. y Heredero Díaz, O. (2015). Propuesta de un modelo genérico de análisis de la estructura de las narrativas transmedia. Icono 14, Revista de Comunicación y Tecnologías Emergentes, 13(2), 260-285. https://doi.org/10.7195/ri14.v13i2.745

Giovagnoli, M. (2017). The Transmedia Way: A Storytellers, Communicators an Designers' Guide to the Galaxy (Digital formato E-Book). ETC Press.

Gomez, J. (2012). The 10 Commandments Of 21st Century Franchise Production [Comercial]. Business Insider. https://www.businessinsider.com/10-commandments-of-21st-century-franchise-production-2012-10

Gosciola, V. (2003). Roteiro para as novas mídias: Do cinema às mídias interativas. Editora SENAC.

Hernández Pérez, M. y Grandío Pérez, M. del M. (2011). Narrativa crossmedia en el discurso televisivo de Ciencia Ficción. Estudio de Battlestar Galactica (2003-2010). Área Abierta, 28(4), 20.

Jenkins, H. (2008). Convergence Culture: La cultura de la convergencia de los medios de comunicación. Paidós.

Jenkins, H., Ford, S. y Green, J. (2015). Cultura Transmedia. La creación de contenido y valor en una cultura en red. Gedisa Editorial.

Kinder, M. (1991). Playing with Power in Movies, Television, and Video Games: From Muppet Babies to Teenage Mutant Ninja Turtles. Universty of California Press.

Klastrup, L. y Tosca, S. (2004). Transmedial Worlds - Rethinking Cyberworld Design. Proceedings International Conference on Cyberworlds. https://doi.org/10.1109/CW.2004.67

\section{осм Observatorio deCibermedios}

\section{https://observatoriocibermedios.upf.edu/}

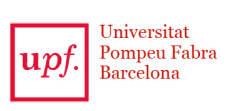

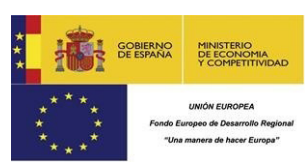

El Observatorio de Cibermedios es una producción del Grupo de Investigación en Documentación Digital y Comunicación Interactiva (DigiDoc) del Departamento de Comunicación de la Universitat Pompeu Fabra.

El Observatorio de Cibermedios (OCM) forma parte del proyecto del Plan Nacional "Narración interactiva y visibilidad digital en el documental interactivo y el periodismo estructurado". RTI2018-095714-B-C21 (MINECO/FEDER), Ministerio de Ciencia, Innovación y Universidades (España). 
Klastrup, L. y Tosca, S. (2013). Cuando los fans se vuelven jugadores: The lord of the Rings desde la perspectiva de los mundos transmedia. En Scolari, C (ed.) Homo Videoludens 2.0: De Pacman a la gamification (pp. 191-220). Universitat de Barcelona. Barcelona.

Lovato, A. (2017). Transmedia desde la universidad Estudio de caso del modelo DocuMedia. CISTI'2017, 734-739. http://www.aisti.eu/ index.php/pt/12-news/37-cisti-2017-12-conferencia-iberica-de-sistemas-e-tecnologias-de-informacao

Mc Luhan, M. y Fiore, Q. (1969). El medio es el masaje. Paidós.

Miller, C. H. (2008). Digital storytelling: A creator's guide to interactive entertainment. Elsevier.

Pérez Pérez, J. (2015). Creando Universos: La narrativa Transmedia. Universitat Oberta de Catalunya. http://openaccess.uoc.edu/ webapps/o2/bitstream/10609/45691/6/joelperezperezTFG0116memoria.pdf

Pratten, R. (2015). Getting Started in Transmedia Storytelling: A Practical Guide for Beginners 2nd Edition. CreateSpace Independent Publishing Platform. https://talkingobjects.files.wordpress.com/2011/08/ book-2-robert-pratten.pdf

Renó, D. (2019). Perspectivas hacia un periodismo post contemporáneo. Revista ComHumanitas, 10(2), 30-50. https://doi.org/10.31207/ rch.v10i2.199

Renó, D. y Flores Vivar, J. (2012). Periodismo Transmedia: Reflexiones y técnicas para el ciberperiodista desde los laboratorios de medios interactivos. Editorial Fragua.

Ruppel, M. (2006). Learning to Speak Braille: Convergence, Diverfence and Cross-Sited Narratives [Tesis De Doctorado, Universidad de Maryland - College Park].

Scolari, C. (2013). Narrativas Transmedia: Cuando los medios cuentan. Ed. Deusto.

Soprani, C. Z. (director) (1934). El Hombre Bestia [Ciencia Ficción]. Argentina: Prince Film.

\section{Propuestas transmediales consultadas}

DCMTeam. (2013). Tras los pasos del Hombre Bestia [Documental Transmedia]. Argentina: UNR http://elhombrebestia.com.ar/front/

DCMTeam. (2014). Mujeres en Venta [Documental Transmedia]. Argentina: UNR. http://www.dcmteam.com.ar/3/transmedia/17/ Mujeres-en-Venta--Documental-Transmedia

DCMTeam. (2018). De Barrio Somos [Documental Transmedia]. Argentina: UNR. http://debarriosomos.com.ar

\section{CV}

María Celeste Marrocco. Licenciada en Cine y TV por la Universidad Nacional de Córdoba, Argentina. Posteriormente completa la Especialización en Video y Tecnologías On Line / Off line, brindada por la misma universidad en colaboración con Media Centre D' Art Disseny Mecad/Esdi y completa la formación de Especialista en Educación y TIC, brindado por el Ministerio de Educación de la Nación, Argentina. También obtiene el título de Doctora en Artes, de la Facultad de Artes, de la Universidad Nac. de Córdoba. Se ha desempeñado como docente en nivel medio, superior y universitario, así como brindado capacitaciones de perfeccionamiento profesional. Ha participado de diversos y numerosos congresos y jornadas relacionadas a la producción audiovisual y multiplataforma a nivel nacional e internacional, publicando diferentes artículos sobre la temática en publicaciones especializadas. Es fotógrafa, realizadora y consultora para producciones multiplataforma.

Toffler, A. (1987). La Tercera Ola. Edivisión.

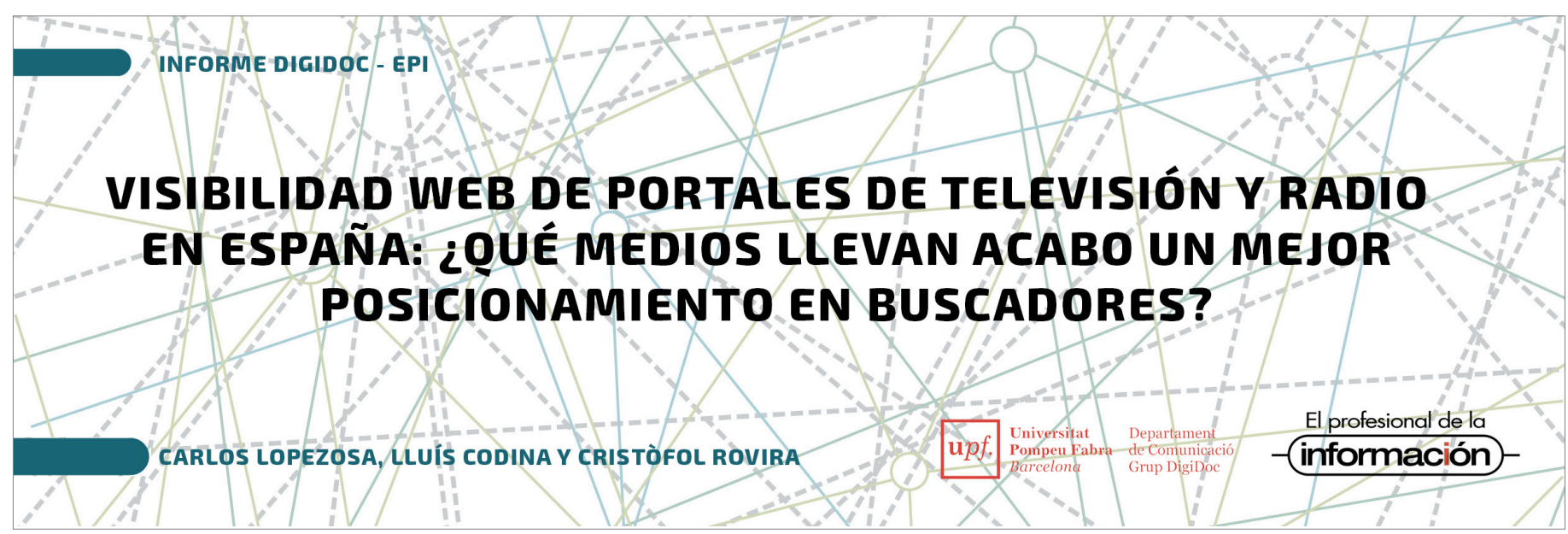

